九州大学学術情報リポジトリ

Kyushu University Institutional Repository

\title{
Effects of Surgical Staff Turning Motion on Airflow Distribution Inside a Hospital Operating Room
}

Wong, Keng Yinn

School of Mechanical Engineering, Faculty of Engineering, Universiti Teknologi Malaysia

Has linda, Mohamed Kamar

School of Mechanical Engineering, Faculty of Engineering, Universiti Teknologi Malaysia

Nazri, Kamsah

School of Mechanical Engineering, Faculty of Engineering, Universiti Teknologi Malaysia

Alia, Sofia Norazam

School of Mechanical Engineering, Faculty of Engineering, Universiti Teknologi Malaysia

https://doi.org/10.5109/2321008

出版情報 : Evergreen. 6 (1)，pp.52-58，2019-03. 九州大学グリーンアジア国際リーダー教育センター バージョン：

権利関係 : 


\title{
Effects of Surgical Staff Turning Motion on Airflow Distribution Inside a Hospital Operating Room
}

\author{
Wong Keng Yinn ${ }^{1}$, Haslinda Mohamed Kamar ${ }^{1,}$, Nazri Kamsah ${ }^{1}$, \\ Alia Sofia Norazam ${ }^{1}$ \\ ${ }^{1}$ School of Mechanical Engineering, Faculty of Engineering, Universiti Teknologi Malaysia, Johor Bahru, \\ Johor, Malaysia
}

*Author to whom correspondence should be addressed, E-mail: haslinda@utm.my

(Received November 21, 2018; accepted March 26, 2019).

\begin{abstract}
This study aims to evaluate the influence of manikin's turning motion on the airflow field in an operating room. A simplified three-dimensional model of the operating room was developed using computational fluid dynamics method. The RNG k- $\varepsilon$ turbulence model was used to predict the airflow distribution. The manikin movement was introduced using a user-defined function code. Results show that the bent-forearm and upright turnings of the manikin could increase the airflow velocity in the surgical zone by $35 \%$ and $23 \%$, respectively.
\end{abstract}

Keywords: computational fluid dynamics, airflow simulation, manikin movement model.

\section{Introduction}

Hospitals require a high level of cleanliness, particularly inside the operating rooms, where surgeons perform surgical procedures on patients. Such requirements will protect patients from possible surgical site infection (SSI) ${ }^{1)}$. Studies have shown that out of 100 operations, approximately 7 patients (Sweden), 15 patients (Brazil), 5 patients (Europe \& USA) and 11 patients (Vietnam) were infected with an SSI 2) 3) 4). The U.S. Department of Health and Human Services (HHS) estimated that annually, there are more than 290,000 cases of SSI, and more than 13,000 infected patients die $^{5}$. SSIs cause an undue financial burden, as the costs of post-surgical treatment are high, ranging from $\$ 400$ to $\$ 30,000$ depending on the types of infection ${ }^{2)}$. SSIs could occur either through direct contact or through the deposition of airborne bacteria-carrying particles (BCP) into the patient's wound. The probability of patients contracting an SSI through direct contact is quite low since all surgical instruments are sterilized before they are used. The deposition of airborne particles is hence identified as the primary cause of SSI. Studies have found that about $98 \%$ of infections in surgical wounds result from airborne $\mathrm{BCP}{ }^{6}$. To overcome the issue of airborne particles settling on a patient, numerous ventilation strategies have been considered ${ }^{7)}$. The ceiling-mounted air supply diffuser and low-level exhaust grilles were found to be one of the most promising ventilation strategies to reduce the particle settlement on a patient ${ }^{8)}$ 9) 10) 11). It utilized the unidirectional downward airflow to provide a sweeping effect of the particles' sources. Under conditions of steady airflow with all staff remaining static, the particles were removed from the vicinity of the surgical zone as intended. However, the effects of the medical staff's movement on the airflow and particle transportation are rarely investigated. So far, studies have reported that an action such as an individual walking or a door opening creates a secondary airflow, which disrupts the main airflow 12) 13) 14) 15) 16). The effect of a staff member's turning motion in an operating room has not been reported. Such consideration is crucial in the operating room, as it interrupts the unidirectional airflow and subsequently affects the dispersion of BCP.

The objective of this study is to assess the influence of surgical staff's turning motion on the airflow field in a hospital operating room. An RNG k- $\varepsilon$ model based on the Reynolds-Averaged Navier-Stokes (RANS) equations was conducted to predict the distribution of air velocity. A parametric study was performed to examine the posture of turning staff on the airflow field inside the operating room. Two types of turning staff with upright posture were considered: bent-forearm and straight-forearm.

\section{Methodology}

\subsection{Description of the Computational Domain}

Computer-Aided Design (CAD) software was used to construct a computational domain that represents a simplified geometry of the operating room, which fulfills the ISO Class-7 specifications. The room has dimensions $6 \mathrm{~m}(\mathrm{~L}) \times 5.5 \mathrm{~m}(\mathrm{~W}) \times 3.0 \mathrm{~m}(\mathrm{H})$, as shown in Fig. 1 . Features of five surgical staffs, surgical lamp, air supply 
system and medical equipment are incorporated into the geometry.

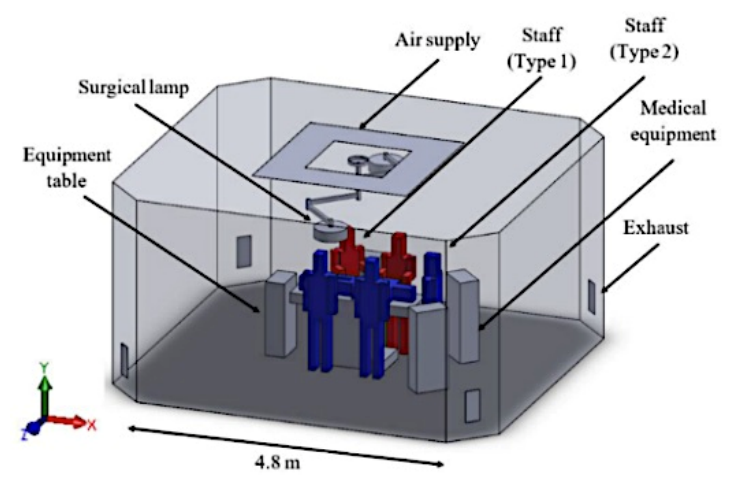

Fig. 1: Simplified geometry of the hospital operating room with surgical staffs and furniture

Cool and clean air is supplied into the operating room through a ceiling-mounted air supply diffuser. The diffuser was equipped with a High-Efficiency Particulate Air (HEPA) filter, which is capable of trapping $99.97 \%$ of particles with sizes larger than $0.3 \mu \mathrm{m}$. About $14 \%$ of the total ceiling area was covered by the air supply diffusers and surgical lamp fixtures. The outgoing air flows via four exhaust grilles placed at the four corners of the wall, $0.25 \mathrm{~m}$ above floor level. This ventilation system functions to filter the unwanted residues from the outdoor air to enter the operating room and to remove any airborne particles through the exhaust grilles. It fulfills the standard ${ }^{17}$ ), which requires that the air supply diffuser should extend a minimum of $305 \mathrm{~mm}$ beyond the footprint of the operating table on each side. The zone bounded by the footprint area is assumed to be the surgical zone, as the surgical procedures are performed within this region.

To reduce the computational time during the flow simulation, the domain was divided into two zones namely the static-mesh zone and the dynamic-mesh zone, as shown in Fig. 2.

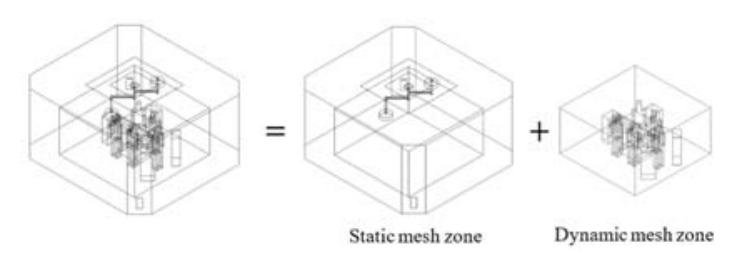

Fig. 2: Mesh zones setup for the computational domain

The static-mesh zone refers to the arrangement of elements that remain unchanged throughout the simulation. In the dynamic-mesh zone, the elements will be re-arranged at the specified time-step, during the simulation. This approach reduces the number of elements involved in the rearrangement at every specified time-step. A total of five surgical staffs were positioned around the operating table with an upright posture. Two pieces of medical equipment, two surgical lamps, two equipment tables, an operating table, and a feature of a patient were incorporated into the operating room geometry. Such physical arrangement has been employed in previous studies ${ }^{18)}{ }^{19}$ ). The dimensions and heat flux released from each feature inside the CFD model of the operating room are tabulated in Table 1. The magnitudes of heat flux released from the surgical staffs, medical equipment, and surgical lamps were obtained from the literature ${ }^{2)}$. Detail dimensions of the surgical staff's features are given in Table 2.

Table 1: Dimensions and heat flux released by features inside the operating room

\begin{tabular}{lcc}
\hline \multicolumn{1}{c}{ Objects } & Dimension (m) & $\begin{array}{c}\text { Heat flux } \\
\left(\mathbf{W} / \mathbf{m}^{2}\right)\end{array}$ \\
\hline $\begin{array}{l}\text { Surgical staff } \\
\text { Medical }\end{array}$ & As described in Table 2 & 110 \\
equipment & $0.5 \times 0.3 \times 1.6(\mathrm{~L} \times \mathrm{W} \times \mathrm{H})$ & 255 \\
Surgical lamp & $0.5 \times 0.15(\mathrm{D} \times$ thickness $)$ & 320 \\
Operating table & $1.9 \times 0.6 \times 0.85(\mathrm{~L} \times \mathrm{W} \times \mathrm{H})$ & - \\
Equipment table & $0.5 \times 0.3 \times 1.1(\mathrm{~L} \times \mathrm{W} \times \mathrm{H})$ & - \\
\hline
\end{tabular}

Two distinct types of upright staff models were incorporated into the case study: the straight-forearm staff and the bent-forearm staff. The former is considered as an assisting staff member watching the surgery whereas the latter is assumed to be a staff member performing the surgical procedures.

Table 2: The dimensions of the surgical staffs' features

\begin{tabular}{|c|c|c|c|c|}
\hline $\begin{array}{c}\text { Manikin } \\
\text { model }\end{array}$ & Name & $\begin{array}{c}\text { Length } \\
(\mathrm{m})\end{array}$ & $\begin{array}{c}\text { Width } \\
\text { (m) }\end{array}$ & $\begin{array}{c}\text { Height } \\
\text { (m) }\end{array}$ \\
\hline & Body & 0.3 & 0.2 & 0.675 \\
\hline & Head & 0.15 & 0.2 & 0.305 \\
\hline & Left \& right hand & 0.1 & 0.1 & 0.575 \\
\hline Type 1 & Left \& right leg & 0.1 & 0.2 & 0.75 \\
\hline & Body & 0.3 & 0.2 & 0.675 \\
\hline & Head & 0.15 & 0.2 & 0.305 \\
\hline & Left \& right arm & 0.1 & 0.1 & 0.3 \\
\hline & $\begin{array}{c}\text { Left \& right forearm } \\
\text { and hand }\end{array}$ & 0.1 & 0.1 & 0.225 \\
\hline & Left \& right leg & 0.1 & 0.2 & 0.75 \\
\hline
\end{tabular}

\subsection{Meshing the Computational Domain}

General-purpose CFD software was used to mesh the geometry of the operating room. Unstructured tetrahedral elements were used for the entire computational domain. Finer elements were specified in regions where there is a 
significant variation in airflow, i.e. the air supply diffuser, exhaust air outlets, surgical staffs, surgical lamps, and furniture. A grid independence test (GIT) was carried out, and the grid convergence index (GCI) was determined to establish the number of elements that could minimize the effects of meshing on the simulation results ${ }^{20)}$. The GIT was performed by carrying out transient flow simulations utilizing six sets of element numbers, namely from 200,000 up to $6,400,000$ elements. For each number of elements used, the airflow velocity along two straight lines that run horizontally and vertically across the operating room was obtained. The data were plotted to examine their variation with a different number of elements used. These plots are shown in Fig. 3. It was observed that the CFD model with 1,600,000 is sufficient to minimize the effects of meshing on the airflow velocity result.

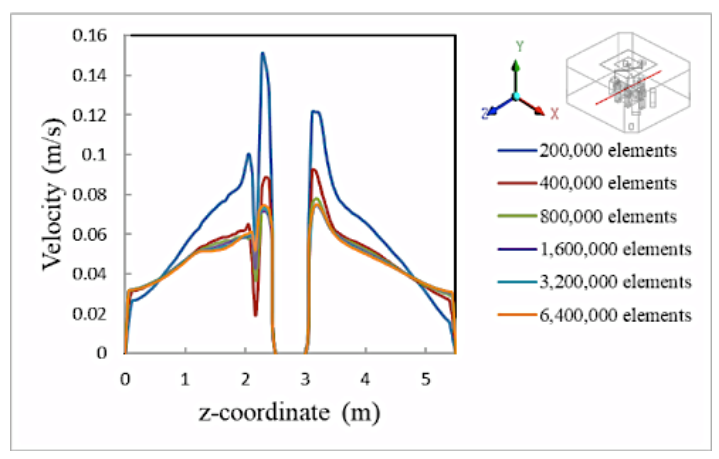

(a)

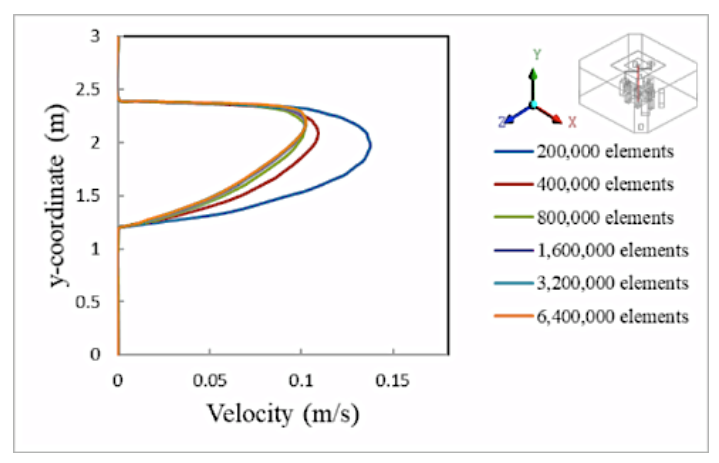

(b)

Fig. 3: Variation of airflow velocity for six different sets of tetrahedral elements along (a) horizontal line, and (b) vertical line.

A GCI was also calculated to estimate the meshing uncertainty. The meshing is considered sufficiently fine when a GCI value falls below 5\%. The GCI was calculated based on Eqn. (1) ${ }^{21)} 22$.

$$
\operatorname{GCI}(u)=\frac{F_{s} \varepsilon_{r m s}}{r^{p}-1}
$$

where $F_{s}$ is the safety factor, with a value of $3, \varepsilon_{r m s}$ is the relative difference between subsequent solutions, $p$ is the order of convergence, with a value of 2 , and $r$ is the ratio of the amount of the fine grids to that of coarse grids. The safety factor $F_{s}$ was arbitrarily set based on the accumulated experience on CFD calculations ${ }^{22)}$. It represents $95 \%$ confidence for the estimated error band. The $\varepsilon_{r m s}$ was defined as given by Eqn. (2) ${ }^{21)}$.

$$
\varepsilon_{r m s}=\sqrt{\frac{\sum_{i=1}^{n}\left(\left(u_{i, \text { coarse }}-u_{i, \text { fine }) / u_{i, f i n e}}\right)^{2}\right.}{n}}
$$

where $\mathrm{u}$ is the airflow velocity. The dimensionless wall distance, $\mathrm{y}^{+}$, was set below 2 to ensure that the near wall mesh was sufficiently fine. It was found that the variations of GCI for the same horizontal and vertical lines across the operating room geometry are less than $5 \%$ when meshing with $1,600,000$ tetrahedral elements was used. Hence, this number of elements was employed in the subsequent CFD flow simulations.

\subsection{Selections and Validation of Airflow Models}

Several flow models are available in the CFD software to simulate the airflow inside the computational domain. The commonly used models for an indoor simulation are standard k- $\varepsilon$, standard k- $\omega$, SST k- $\omega$, and RNG k- $\varepsilon$ models. In this study, all these flow models were examined so that only the most appropriate model was utilized for the subsequent CFD flow simulations. The data obtained from the literature ${ }^{23)}{ }^{24)}$ were employed to compare with the simulated result under both steady- and transient-flow conditions. Both cases have high similarity in the indoor environment and airflow conditions. The studies were conducted in an ISO Class-5 single-bed ward and an environmental chamber, respectively. The results of the CFD flow simulation were compared with similar results obtained from the literature ${ }^{22}$ ). These comparisons are shown in Fig. 4. For the results of CFD simulation in this study, the airflow velocity data were obtained on two planes, L1 and L2, that run across the operating room geometry. On both planes, two horizontal lines on which airflow velocity data were obtained for comparison; one is at a height of $0.8 \mathrm{~m}$ and the other at a height of $1.2 \mathrm{~m}$ from the floor of the operating room model.

As seen in Fig. 4, the airflow velocity obtained using the RNG k- $\varepsilon$ and SST k- $\omega$ model agreed well with the published data. The relative error between the CFD simulation results and published data should be below $10 \%$ to ensure the CFD model is reliable ${ }^{25}$. The relative error can be determined based on Eqn. (3).

$$
\text { Relattve error }=\frac{\text { Measurement value }- \text { Simulated value }}{\text { Measurement value }}
$$

In the present work, both the RNG $\mathrm{k}-\varepsilon$ and SST k- $\omega$ produced relative errors that are $8 \%$ and $9 \%$, respectively. 
Therefore, it is safe to assume that the CFD model was well validated against the published results. The RNG $\mathrm{k}-\varepsilon$ flow model was used for the subsequent CFD flow simulations because it produced the lowest relative error.

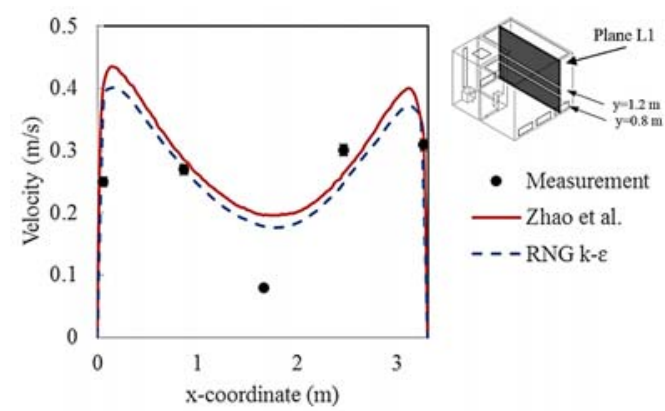

(a)

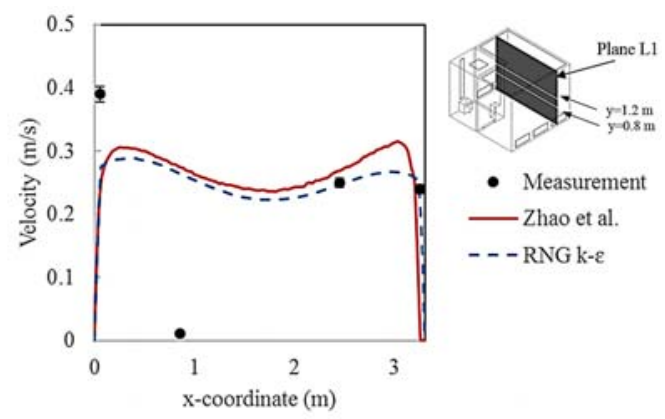

(b)

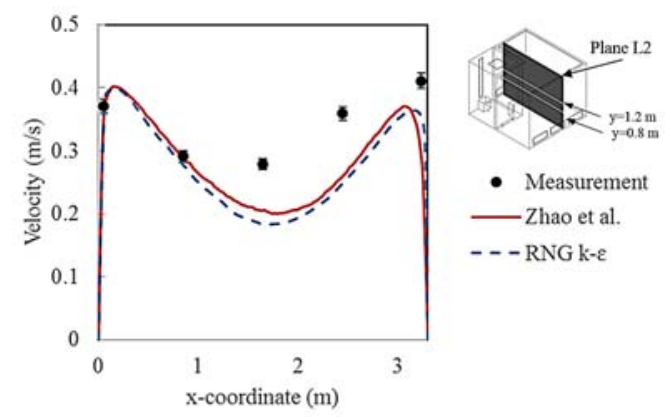

(c)

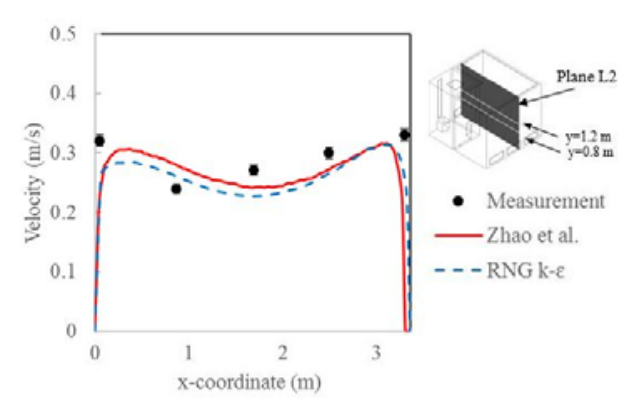

(d)

Fig. 4: Comparisons of airflow velocity distributions (a) on plane L1 at the height of $0.8 \mathrm{~m},(\mathrm{~b})$ on plane L1 at the height of 1.2 $\mathrm{m}$, (c) on plane L2 at the height of $0.8 \mathrm{~m}$, (d) on plane L2 at the height of $1.2 \mathrm{~m}$, from the floor of the room.

\subsection{Boundary Conditions and Solution Setup}

An inlet airflow velocity was specified at the ceiling mounted air supply diffusers. The magnitude of the airflow velocity was set at $0.43 \mathrm{~m} / \mathrm{s}$ and the air temperature was set at $19^{\circ} \mathrm{C}$. All airflow boundary conditions were specified in the direction normal to the respective surfaces, with a turbulence intensity of $5 \%$. A zero-gauge pressure condition was set at all the air exhaust grilles, which served as the air outlets. The air inside the operating room was assumed to be an incompressible substance. The staff-turning motion velocity was set at $1.57 \mathrm{rad} / \mathrm{s}$, which was determined from the experiment. A user-defined function (UDF) code written in $\mathrm{C}++$ language was compiled into the CFD software, to control the turning motion of the surgical staff. A summary of the commands in the code is shown in Table 3.

Table 3: Commands in the UDF code

\begin{tabular}{cc}
\hline Time & Turning angular velocity \\
\hline $\mathbf{0 ~ s}<$ time $\leq 1 \mathrm{~s}$ & $1.57 \mathrm{rad} / \mathrm{s}($ clockwise direction $)$ \\
$1 \mathrm{~s}<$ time $\leq \mathbf{1 0 ~ s}$ & $0.00 \mathrm{rad} / \mathrm{s}$ \\
\hline
\end{tabular}

During the CFD flow simulation, only one surgical staff performs the turning motion, through a rotation angle of $90^{\circ}$. The remaining surgical staffs were kept in a static posture throughout the entire simulation. The turning motion begins at a time of $0 \mathrm{~s}$ and stopped at a time of $1 \mathrm{~s}$. From $1 \mathrm{~s}$ onwards, all the surgical staffs remained stationary. The total simulation time was set at $10 \mathrm{~s}$.

To assess the effects of surgical staff's posture on the airflow distribution, two forearm positions of the moving surgical staff were considered, namely a bent-forearm condition (model type 2) and a straight-forearm condition (model type 1). For both cases, the turning direction, turning angle, and velocity remained the same, that is, clockwise, $90^{\circ}$, and $1.57 \mathrm{rad} / \mathrm{s}$, respectively.

\section{Results and Discussion}

Figure 5 shows contour plots of airflow velocity on a vertical plane at a location $\mathrm{x}=2.6 \mathrm{~m}$, for different arm bending positions of the turning surgical staff. It can be observed that a high airflow velocity is concentrated in the upper region of the surgical zone, and gradually decreasing towards the lower corners of the operating room. The airflow from the supply diffusers appears to be interrupted by the surgical lamps. At the surgical staff's head level, the airflow velocity has decreased to approximately $0.12 \mathrm{~m} / \mathrm{s}$. 


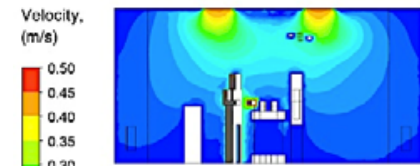

(a)

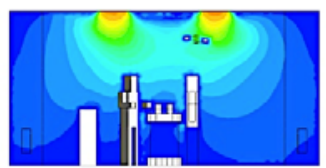

(c)

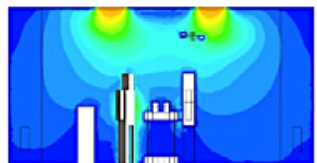

(b)

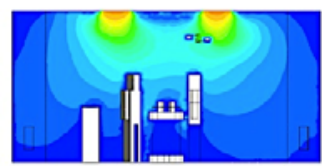

(d)
Fig. 5: Airflow distribution on a vertical plane of location $\mathrm{x}=2.6 \mathrm{~m}$, for (a) bent-forearm, (b) straight-forearm, (c) bent-forearm, (d) straight-forearm. Figures (a) and (b) are for time $t=1 \mathrm{~s}$ and figures (c) and (d) are for time $t=10 \mathrm{~s}$.

The airflow velocity was further reduced to $0.08 \mathrm{~m} / \mathrm{s}$ at a height of $1.2 \mathrm{~m}$ above floor level. A stagnant airflow was found in two regions namely below the operating table and in the gap between the surgical staffs' legs. The stagnant airflow is undesirable as it could reduce the air change rate and increases the tendency for airborne contamination to accumulate in these regions.

It can also be observed in Fig. 5 that the airflow distribution at $1 \mathrm{~m}$ away from the turning surgical staff was not much affected by the turning motion. Also, the airflow distribution around the turning surgical staff was affected by the staff's posture. At the time $t=1 \mathrm{~s}$, the airflow velocity around the bent-forearm staff (Fig. 5(a)) is about $12 \%$ higher than that around the straight-forearm position (Fig. 5(b)). However, at the time $t=10 \mathrm{~s}$, the average airflow velocity around the turning surgical staff was almost the same for both cases, as seen in Fig. 5(c) and Fig. 5(d). Under the steady and stationary conditions, the variation in the airflow velocity between the two cases is not noticeable. As also observed from Fig. 5, obstacles, such as medical equipment, equipment table, operating table, and surgical staffs were found to block the supply of air to the rest of the operating room area. The airflow distribution on a horizontal plane at location $\mathrm{y}=1.2 \mathrm{~m}$, at a different time, for a turning surgical staff with a bent forearm, is shown in Fig. 6(a). It is seen in Fig. 6 that the turning motion created a high airflow velocity in the vicinity of the turning surgical staff, especially at the tip of his hand. The movement tends to push the air in the turning direction. During the motion, the airflow distribution within $0.5 \mathrm{~m}$ radius from the turning surgical staff was significantly increased. A maximum airflow velocity of $0.47 \mathrm{~m} / \mathrm{s}$ was obtained throughout the entire turning movement. A swirling airflow was observed around the bent forearm of the surgical staff. After turning, the surgical staff became static and the airflow condition returns to a steady state

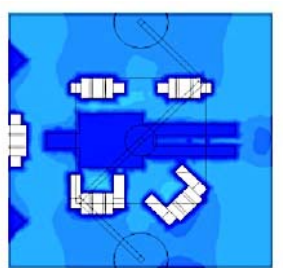

Time $=\mathbf{0}$ s

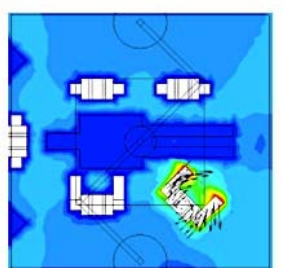

Time $=1.0 \mathrm{~s}$

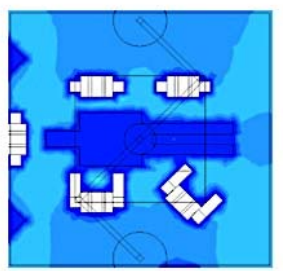

Time $=\mathbf{5 . 0} \mathrm{s}$

(a)

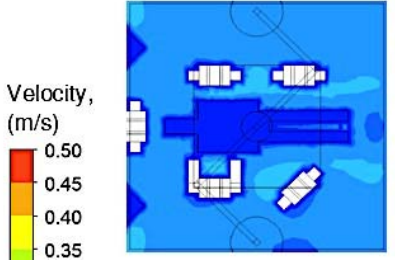

Time $=0$ s

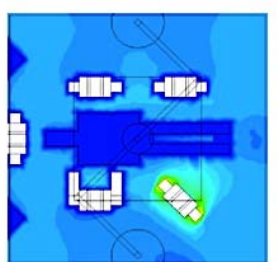

Time $=1.0 \mathrm{~s}$

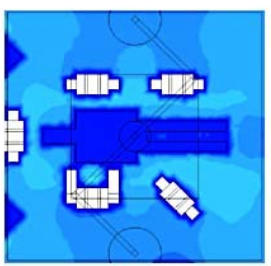

Time $=\mathbf{5 . 0} \mathrm{s}$

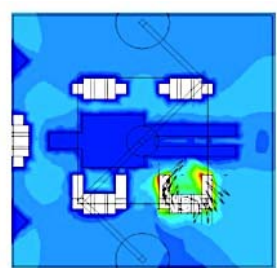

Time $=0.5 \mathrm{~s}$

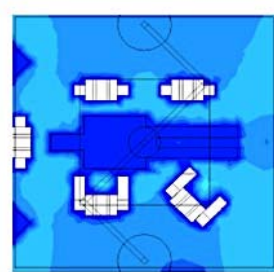

Time $=1.5 \mathrm{~s}$

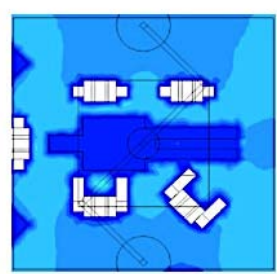

Time $=10 \mathrm{~s}$

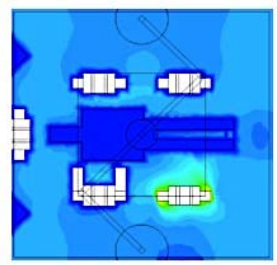

Time $=0.5 \mathrm{~s}$

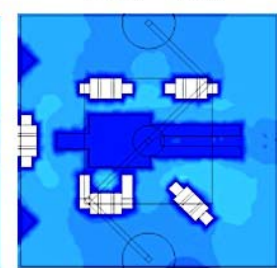

Time $=1.5 \mathrm{~s}$

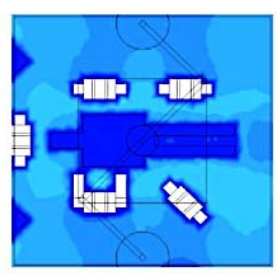

Time $=10 \mathrm{~s}$ (b)

Fig. 6: Airflow distribution on a horizontal plane at location $\mathrm{y}=1.2 \mathrm{~m}$ from floor level, at a different time, (a) for the turning surgical staff with a bent forearm, and (b) for an upright turning staff with a straight-forearm. 
within $5 \mathrm{~s}$

The airflow distribution on a horizontal plane at a location $\mathrm{y}=1.2 \mathrm{~m}$ from the floor, at a different time, for an upright turning staff with a straight-forearm is shown in Fig. 6(b). Compared to the bent-forearm position, the airflow velocity produced by the straight-forearm surgical staff is significantly lower. The highest airflow velocity was found to be $0.36 \mathrm{~m} / \mathrm{s}$. At the end of the movement, the airflow condition reached a steady state at a slightly shorter time than that in the former case, i.e. earlier by $0.4 \mathrm{~s}$. At the time $\mathrm{t}=10 \mathrm{~s}$, the difference in the airflow velocity magnitude between the two cases was negligibly small.

\section{Conclusion}

Computational fluid dynamics method was employed to carry out turbulent flow simulation on a simplified model of a hospital operating room furnished with a vertical air supply system. The goal was to examine the effect of turning motion of one of the surgical staffs on the airflow velocity distribution inside the room. Two posture positions were investigated during the rotational motion of the staff namely straight-arm and bent-arm. Results of the CFD flow simulations show that the airflow distribution around the turning surgical staff was marginally affected by the staff's arm posture. At a simulation time $t=1 \mathrm{~s}$, the airflow velocity around the bent-forearm staff is about $12 \%$ higher than that around the straight-forearm position. However, at a simulation time $\mathrm{t}=10 \mathrm{~s}$, the airflow velocity around the turning surgical staff was almost the same for both cases. The airflow distribution within $0.5 \mathrm{~m}$ radius from the turning surgical staff was significantly increased. A maximum airflow velocity of $0.47 \mathrm{~m} / \mathrm{s}$ was obtained throughout the entire turning movement. Compared to the bent-forearm position, the airflow velocity produced by the straight-forearm surgical staff is significantly lower. The highest airflow velocity was found to be $0.36 \mathrm{~m} / \mathrm{s}$. At the end of the movement, the airflow condition reached a steady state at a slightly shorter time than that in the former case, i.e. earlier by $0.4 \mathrm{~s}$. At the simulation time $\mathrm{t}=10 \mathrm{~s}$, the difference in the airflow velocity magnitude between the two cases was negligibly small.

\section{Acknowledgments}

The authors are grateful to the Universiti Teknologi Malaysia for providing the funding for this study, under the vote numbers $14 \mathrm{H} 64$ and $20 \mathrm{H} 44$.

\section{References}

1) X. He, S. Karra, P. Pakseresht, S.V. Apte, Effect of heated-air blanket on the dispersion of squames in an operating room, International Journal for Numerical
Methods in Biomedical Engineering 34(5), 1-24 (2017).

2) S. Sadrizadeh, S. Holmberg, Effect of a portable ultra-clean exponential airflow unit on the particle distribution in an operating room, Particuology 18, 170-178 (2015).

3) M.A. Melhado, J. Hensen, M. Loomans, Review of ventilation systems in operating rooms in view of infection control, Proceedings of the 6th Int. Postgraduate Research Conf. in the Built and Human Environment, Technische Universiteit Delft, pp. 478-487 (2006).

4) D. Nguyen, W.B. MacLeod, D.C. Phung, Q.T. Cong, V.H. Nguyen, D.H. Hamer, Incidence and predictors of surgical-site infections in Vietnam, Infection Control \& Hospital Epidemiology 22(08), 485-492 (2001).

5) J.A. Wagner, K.J. Schreiber, Improving operating room contamination control, ASHRAE Journal 56(2), 18 (2014).

6) W. Whyte, R. Hodgson, J. Tinkler, The importance of airborne bacterial contamination of wounds, Journal of hospital infection 3(2), 123-135 (1982).

7) A.C. Vogelsang, P. Forander, M. Arvidsson, P. Lowenhielm, Effect of mobile laminar airflow units on airborne bacterial contamination during neurosurgical procedures, Journal of Hospital Infection, 99(3), 271-278 (2018).

8) J. Cho, K. Woo, B.S. Kim, Improved ventilation system for removal of airborne contamination in airborne infectious isolation rooms, ASHRAE Journal 61(2), 8-21, (2019).

9) G. Cao, A.M. Nilssen, Z. Cheng, L. Stenstad, A.Radtke, J.G. Skogas, American Journal of Infection Control 1-7 (2018).

10)C. Wang, S. Holmberg, S. Sadrizadeh, Numerical study of temperature-controlled airflow in comparison with turbulent mixing and laminar airflow for operating room ventilation, Building and Environment 144, 45-56 (2018).

11) S.T. Lee, C.C. Liang, T.Y. Chien, F.J. Wu, K.C. Fan, G.H. Wan, Effect of ventilation rate on air cleanliness and energy consumption in operation rooms at rest, Environmental Monitoring and Assessment 190(3), 178 (2018).

12) Y. Tao, K. Inthavong, J. Tu, Computational fluid dynamics study of human-induced wake and particle dispersion in indoor environment, Indoor and Built Environment 26(2), 185-198 (2006). 
13)J. Teter, I. Guajardo, T. Al-Rammah, G. Rosson, T.M. Perl, M. Manahan, Assessment of operating room airflow using air particle counts and direct observation of door openings, American Journal of Infection Control 45(5), 477-482 (2017).

14)C. Li, and K. Ito, Performance evaluation of industrial air-shower in removal of gas-and liquid-phase contaminants from human body, Evergreen 1(1), 40-47, (2014).

15)J. Therkorn, D. Drewry, T. Pilholski, K.S. Saliba, G. Bova, L.L. Maragakis, B. Garibaldi, L. Sauer, Impact of air-handling system exhaust failure on dissemination pattern of simulant pathogen particles in a clinical biocontainment unit, Indoor Air 29(1), 143-155 (2019).

16)S. Sadrizadeh, J. Pantelic, M. Sherman, J. Clark, O. Abouali, Airborne particle dispersion to an operating room environment during sliding and hinged door opening, Journal of Infection and Public Health 11(5), 631-635 (2018).

17)A.S.H.R.A.E. Standard, Standard $170 \quad-\quad 2008$, Ventilation of Health Care Facilities (2008).

18)C. Balocco, G. Petrone, G. Cammarata, P. Vitali, R. Albertini, C. Pasquarella, Indoor air quality in a real operating theatre under effective use conditions, Journal of Biomedical Science and Engineering 7(11), 866 (2014).

19)T.-T. Chow, J. Wang, Dynamic simulation on impact of surgeon bending movement on bacteria-carrying particles distribution in operating theatre, Building and Environment 57, 68-80 (2012).

20)N. Kamsah, H.M. Kamar, M.I. Alhamid, W.K. Yinn, Impacts of temperature on airborne particles in a hospital operating room, Journal of Advanced Research in Fluid Mechanics and Thermal Sciences 44(1), 12-23 (2018).

21)S. Sadrizadeh, S. Holmberg, P.V. Nielsen, Three distinct surgical clothing systems in a turbulent mixing operating room equipped with mobile ultraclean laminar airflow screen: A numerical evaluation, Science and Technology for the Built Environment 22(3), 337-345, (2016).

22)L. Kwaśniewski, Application of grid convergence index in FE computation, Bulletin of the Polish Academy of Sciences: Technical Sciences 61(1), 123-128 (2013).

23)B. Zhao, C. Yang, C. Chen, C. Feng, X. Yang, L. Sun, W. Gong, L. Yu, How Many Airborne Particles Emitted from a Nurse will Reach the Breathing
Zone/Body Surface of the Patient in ISO Class-5 Single-Bed Hospital Protective Environments? - A Numerical Analysis, Aerosol Science and Technology 43(10), 990-1005 (2009).

24)J. Wang, Influence of human movement on transport of airborne infectious particles in hospital environment, City University of Hong Kong, (2013).

25)C. Yang, X. Yang, T. Xu, L. Sun, W. Gong, Optimization of bathroom ventilation design for an ISO Class 5 clean ward, Building Simulation, Springer, pp. 133-142 (2009). 